Supporting information

\title{
Dependency of electrochemical performances of silicon lithium ion batteries on glycosidic linkages of polysaccharide binders
}

Da-eun Yoon, ${ }^{\dagger}{ }^{\S}$ Chihyun Hwang, ${ }^{\dagger}, \S, *$ Na-Ri Kang, ${ }^{\dagger, \|}$ Ungju Lee, ${ }^{\perp}$ Dongjoon Ahn, ${ }^{\perp} J u-$ Young Kim ${ }^{\star, " ~}, \#$ and Hyun-Kon Song ${ }^{\dagger, *}$

${ }^{\dagger}$ School of Energy and Chemical Engineering, UNIST, Ulsan 689-798, Korea

${ }^{\star}$ School of Materials Science and Engineering, UNIST, Ulsan 689-798, Korea

" KIST-UNIST Ulsan Center for Convergent Materials, UNIST, Ulsan 689-798, Korea

${ }^{\perp}$ GS Energy R\&D Center, GS Energy Corp., Seoul 134-848, Korea

${ }^{\#}$ IBS Research Center for Multidimensional Carbon Materials, UNIST, Ulsan 689-798, Korea

${ }^{\S}$ These authors contributed equally to this work

*The authors to whom correspondence should be addressed

E-mail Address: chhwang@unist.ac.kr (C.H.), philiphobi@hotmail.com (H.-K.S.) 


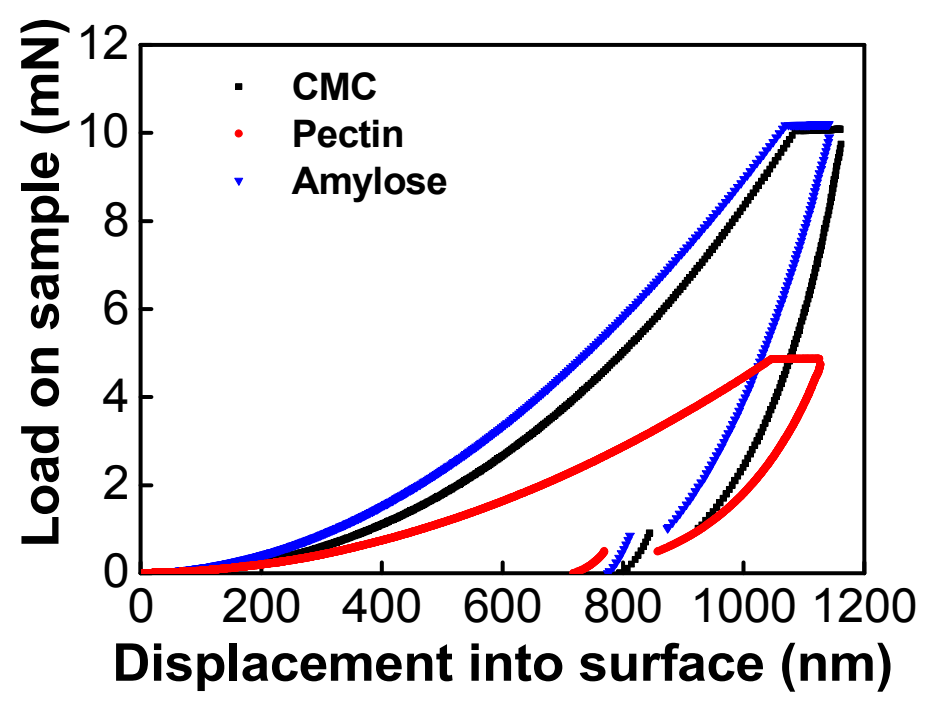

Fig. S1 Force-displacement curves by nano-indentation. 

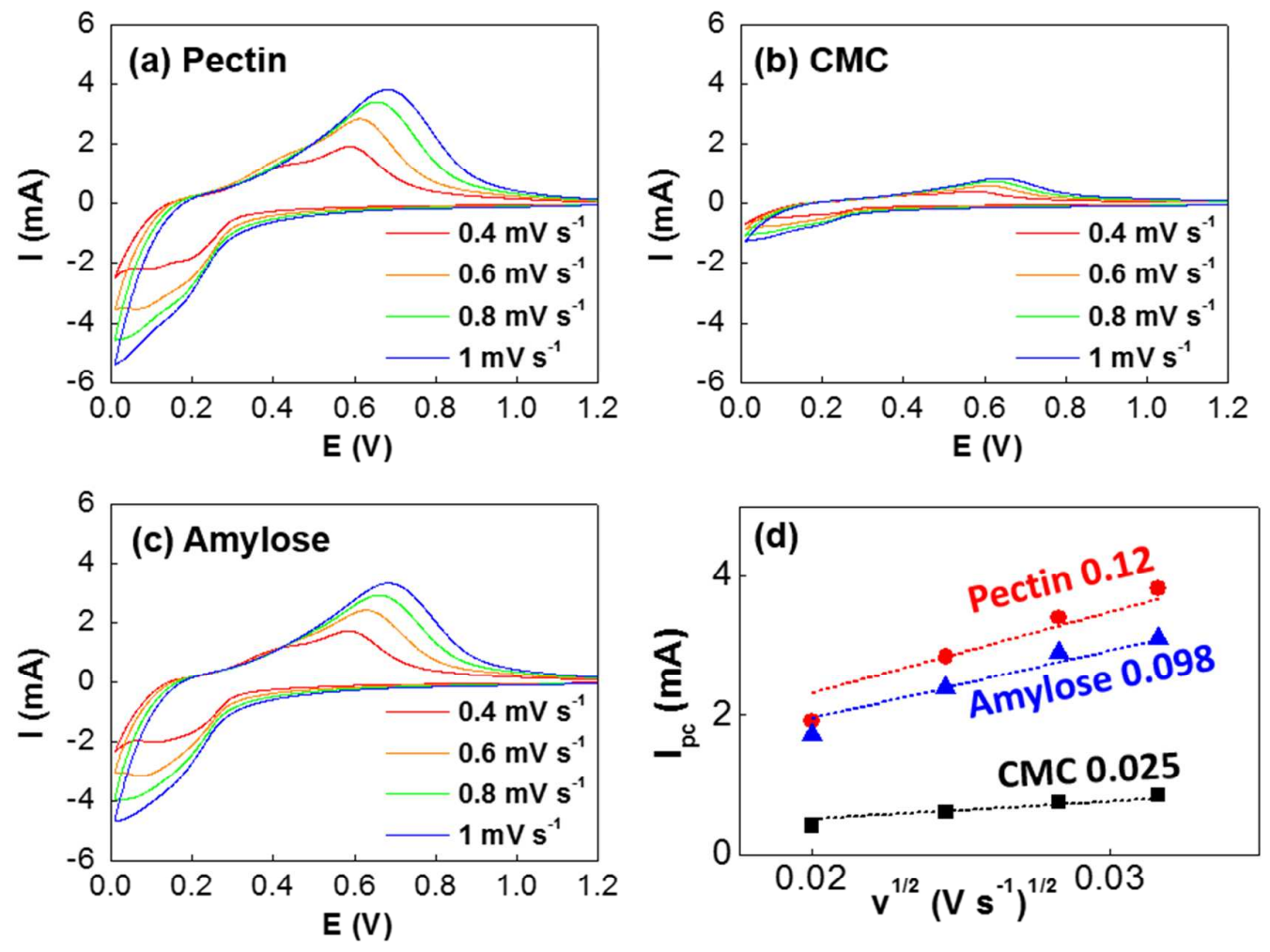

Fig. S2 Electroactive surface area (ECSA). (a to c) Cyclic voltammograms of silicon electrodes after a process forming the solid-electrolyte interphase layers. The binders used for the electrodes were indicated. (d) The relationship between cathodic peak currents $\left(\mathrm{I}_{\mathrm{pc}}\right)$ and the square root of the scan rate. ECSA $\left(\mathrm{A}\right.$ in $\left.\mathrm{cm}^{2}\right)$ was calculated from the slopes by RandlesSevcik equation: $i_{p c}=\left(2.69 \times 10^{5}\right) n^{3 / 2} A D_{0}^{1 / 2} C_{0}^{*} v^{1 / 2} \quad$ where $i_{p c}$ is the peak current (A) at a given potential, $v$ is the scan rate $\left(\mathrm{mV} \mathrm{s}^{-1}\right), C_{0}^{*}$ is bulk concentration of $\mathrm{Li}$ ions, $D_{0}$ is the diffusion coefficient of $\mathrm{Li}$ ion $\left(\mathrm{cm}^{2} \mathrm{~S}^{-1}\right)$ and $n$ is the number of transferred electron ( 1 for $\left.\mathrm{Li}^{+}\right)$. 


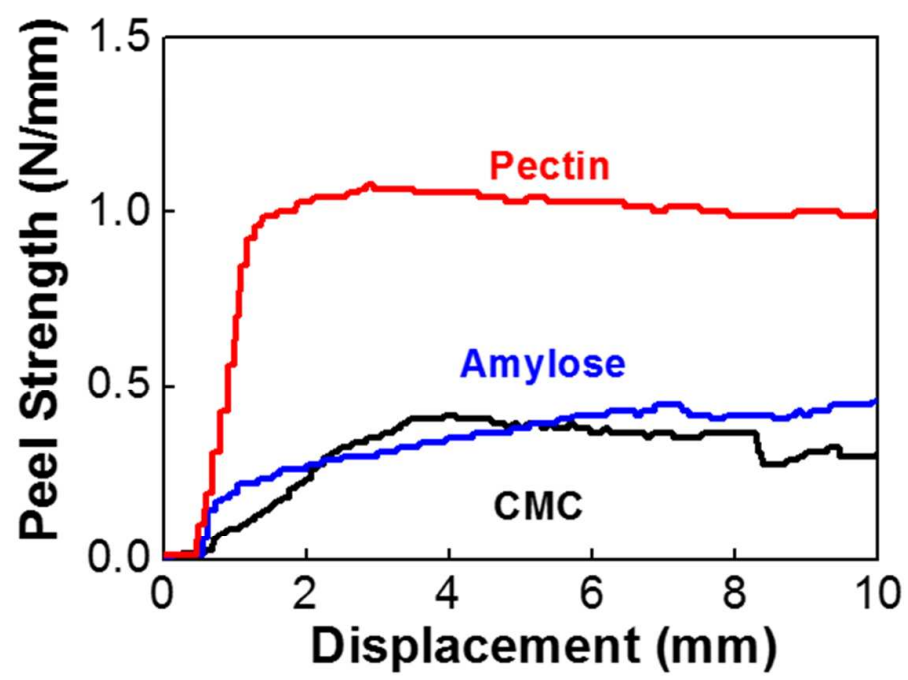

Fig. S3 Adhesion properties of composite electrode films on current collectors. 50 umthick composite electrodes films on copper current collectors were used for the 180 degree adhesive peel strength tests. The composite films consisted of pectin were peeled off from copper current collector by the force which is 3 times larger than that of Amylose or CMCbased composite films. 


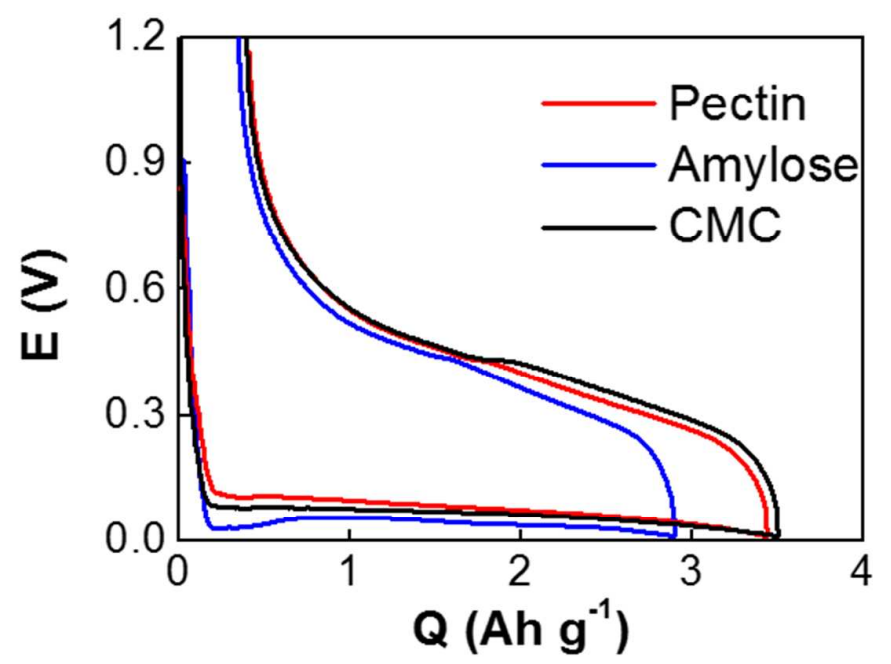

Fig. S4 Potential profiles at the first galvanostatic charge and discharge.
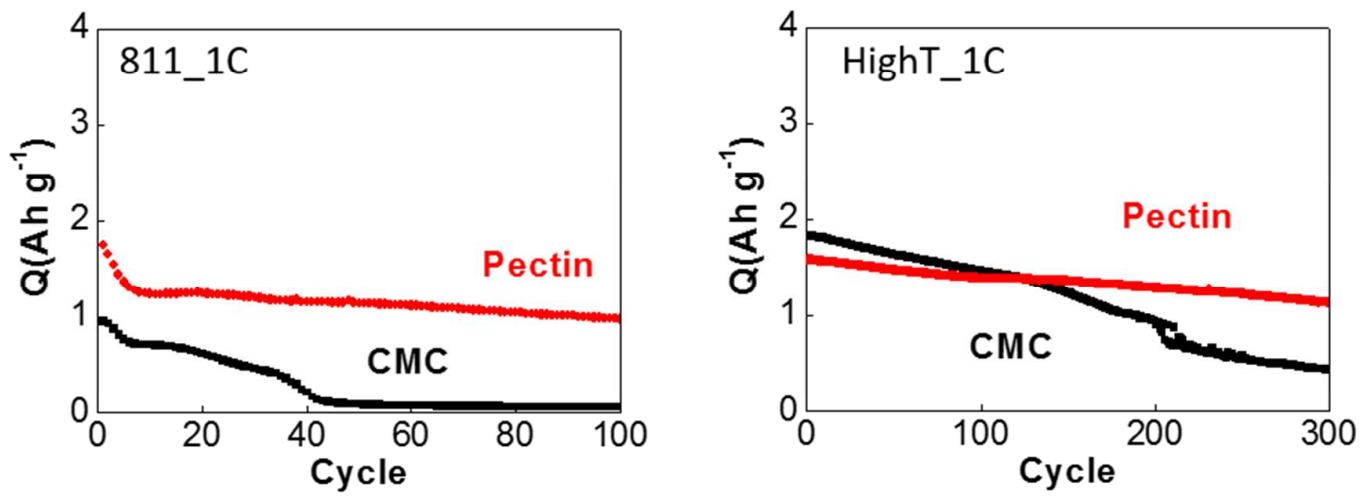

Fig. S5 Cyclability test of high loading cells based on Pectin or $\mathrm{CMC}$ at $1 \mathrm{C}$ with room and high temperature. 